\title{
High Genetic Diversity and Insignificant Interspecific Differentiation in Opisthopappus Shih, an Endangered Cliff Genus Endemic to the Taihang Mountains of China
}

\author{
Rongmin Guo, ${ }^{1}$ Lihua Zhou, ${ }^{1}$ Hongbo Zhao, ${ }^{1,2}$ and Fadi Chen ${ }^{3}$ \\ ${ }^{1}$ Department of Ornamental Horticulture, School of Landscape Architecture, Zhejiang Agriculture and Forestry University, \\ Linian, Hangzhou, Zhejiang 311300, China \\ ${ }^{2}$ Nurturing Station for State Key Laboratory of Subtropical Silviculture, Lin'an, Hangzhou 311300, China \\ ${ }^{3}$ College of Horticulture, Nanjing Agricultural University, Nanjing 210095, China
}

Correspondence should be addressed to Hongbo Zhao; zhaohb@zafu.edu.cn

Received 29 September 2013; Accepted 19 November 2013

Academic Editors: A. Belyayev and K. Vandepitte

Copyright (C) 2013 Rongmin Guo et al. This is an open access article distributed under the Creative Commons Attribution License, which permits unrestricted use, distribution, and reproduction in any medium, provided the original work is properly cited.

\begin{abstract}
Opisthopappus Shih is endemic to the Taihang Mountains, China. It grows in the crevice of cliffs and is in fragmented distribution. This genus consists of two species, namely, O. taihangensis (Ling) Shih and O. longilobus Shih, which are both endangered plants in China. This study adopted intersimple sequence repeat markers (ISSR) to analyze the genetic diversity and genetic structure from different levels (genus, species, and population) in this genus. A total of 253 loci were obtained from 27 primers, 230 of which were polymorphic loci with a proportion of polymorphic bands $(P P B)$ of up to $90.91 \%$ at genus level. At species level, both $O$. taihangensis $(P P B=90.12 \%, H=0.1842$, and $I=0.289)$ and $O$. longilobus $(P P B=95.21 \%, H=0.2226$, and $I=0.3542)$ have high genetic diversity. Their respective genetic variation mostly existed within the population. And genetic variation in $O$. longilobus (84.95\%) was higher than that in O. taihangensis (80.45\%). A certain genetic differentiation among populations in O. taihangensis was found $\left(G_{s t}=0.2740, \Phi_{s t}=0.196\right)$ and genetic differentiation in O. longilobus was very small $\left(G_{s t}=0.1034, \Phi_{s t}=0.151\right)$. Gene flow in different degrees $\left(N_{m}=1.325\right.$ and 4.336, resp.) and mating system can form the existing genetic structures of these two species. Furthermore, genetic differentiation coefficient $\left(G_{s t}=0.0453\right)$ between species and the clustering result based on the genetic distance showed that interspecific differentiation between $O$. taihangensis and O. longilobus was not significant and could occur lately.
\end{abstract}

\section{Introduction}

Opisthopappus Shih (Asteraceae) is a genus of perennial herbaceous plants with two species, namely, O. taihangensis (Ling) Shih and O. longilobus Shih [1]. These two species are endemic to the Taihang Mountains (China) on the borders between Shanxi, Hebei, and Henan provinces. They grow mostly on cliff cracks, rock gaps in open forests below cliffs, and infertile soil at an elevation of $1000 \mathrm{~m}$ [1]. The flowers are white and large, with remarkably high ornamental and medicinal values [2] and potential genetic resource for chrysanthemum improvement [3-5]. Given the changes in their habitats and manmade damage, their distribution range is decreasing continuously. At present, these species are in an endangered status, listed as national rare and endangered plants in China [6]. O. taihangensis and O. longilobus can be distinguished according to their leaf morphology and the presence or absence of bracts below involucres [1]. The former is distributed in the south of the Taihang Mountain, mainly in Henan and Shanxi; meanwhile, the latter is distributed in the north of the Taihang Mountains, mainly in Hebei. The distribution of these two species basically regards the border between Hebei and Henan $\left(36.07^{\circ} \mathrm{N}\right.$ latitude) as the boundary. Based on relative specimen records, an overlapping distribution of these two species exists in the Linzhou district of the north of Henan.

Daxinganling Mountains-Taihang Mountains-Wu Mountains-Xuefeng Mountains is the borderline of the second and third classes of China Relief. The Taihang Mountains 
is northeast-southwest trend mainly but some parts nearly south-north trend, with the terrain of high north and low south. The altitude of most parts is above $1,200 \mathrm{~m}$. The mountain is precipitous in the east and gradual in the west. Shanxi plateau is connected to the west, and the east part is from middle mountains, low mountains, hills to plains. This terrain allows the growth of rich seed plants in this area. The geographic distribution type of genera in seed plants is diversiform with a great amount of ancient, relict, original and endemic taxa of China, in which Opisthopappus and Taihangia Yu et Li are endemic taxa in this area [1,7-9].

Generally, species with small geographic ranges tend to maintain less genetic diversity than those that are geographically widespread [10]. Several plant species distributed in cliffs show a relatively low genetic diversity [11-14], whereas a few of which have high genetic diversity $[12,15,16]$. High genetic diversity maintained in rare plants is attributable to many factors [17], such as the recent reduction of population size plus insufficient time for isolation, extensive and recurrent gene flow, outcrossing, and fruit dispersal via wind [18-20]. As an ancient habitat, cliffs provide a refuge for plants distributed therein to escape animal feed, interspecies competition, and human disturbance. However, a great heterogeneity also exists on a small scale; for example, differences are found in the proportion of plants to cliff cracks, soil quantity and quality, rock type, weathering degree, and number of surrounding plants [15]. Meanwhile, the differences in the orientation of vertical cliffs also cause differences in illumination, temperature, relative humidity, soil moisture, plant density, and wind speed [21]. This type of local environment diversity causes plants to exhibit polymorphism, which eventually results in high genetic diversity in populations $[15,16]$. In Lloydia serotina, species in cliffs have similar or higher genetic diversity than those in other areas [12]. Taihangia rupestris Yu et Li $[22,23]$ also shows high genetic diversity. The results of cluster analysis show that T. rupestris var. rupestris and $T$. rupestris var. ciliate have significant genetic differentiation.

Currently, studies on Opisthopappus mainly focus on tissue culture [24, 25], karyokinesis [26], meiosis [27, 28], intergeneric crossing [3, 5], pollen morphology [29], and phylogenetic evolution [4]. Wang and Yan [30] reported population genetic structure of two species in Opisthopappus by sequence related amplified polymorphism markers (SRAP). The results showed high genetic diversity existed in populations of the two species. The main aims of this study is to evaluate the genetic diversity and population genetic structure from different levels (genera, species, and populations) in Opisthopappus by adopting the inter-simple sequence repeat (ISSR) molecular marker. Furthermore, according genetic variation and differentiation, interspecific relationship and differentiation were analyzed and realized. The results can provide scientific data and theoretical foundation for the effective protection, sustainable development, and utilization of Opisthopappus species.

\section{Materials and Methods}

Study Species. Six natural populations consisting of three $O$. taihangensis (i.e., YTS, GS, and WML) and three O. longilobus

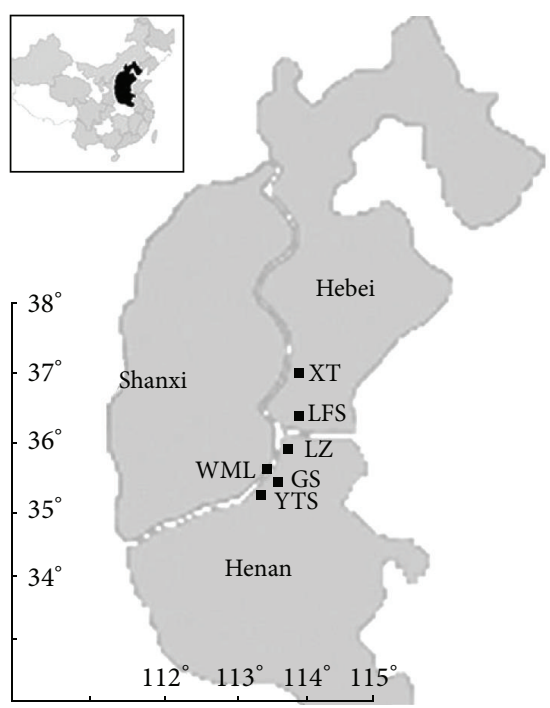

FIGURE 1: Geographic distribution and sampling sites in Opisthopappus.

(LZ, LFS, and XT) populations were collected from the Taihang Mountains in Henan, Shanxi, and Hebei province to serve as materials (Figure 1). A total of 200 individuals were collected (Table 1). The spacing distance between individuals was more than $3 \mathrm{~m}$. Fresh leaves in robust growth were selected for rapid drying using anhydrous silica gel. After drying completely, the leaves were placed in an ultra-cold storage freezer for cold storage.

Extraction of Genome DNA and ISSR-PCR Amplification. An ample amount of dried leaves was taken to extract genomic DNA using the improved CTAB method [31]. The mass and content of DNA were measured using a spectrophotometer to dilute it to $20 \mathrm{ng} / \mu \mathrm{L}$. Twenty-seven primers with high polymorphism and good repeatability were screened from 54 ISSR primers for PCR amplification. The total volume of the ISSR-PCR reaction system was $20 \mu \mathrm{L}$, including $20 \mathrm{ng}$ to $50 \mathrm{ng}$ template DNA, $1.5 \mathrm{mmol} / \mathrm{L} \mathrm{Mg}^{2+}, 1 \times \mathrm{Taq}$ DNA polymerase buffer solution (containing $10 \mathrm{mmol} / \mathrm{L}$ Tris-Hcl, $50 \mathrm{mmol} / \mathrm{L} \mathrm{Kcl}, \mathrm{pH} 9.0), 1.0 \mu \mathrm{mol} / \mathrm{L}$ primer, $0.25 \mathrm{mmol} / \mathrm{L}$ dNTPS, and $1.0 \mathrm{U}$ Taq DNA polymerase. The amplification program used was as follows: predenaturation for $5 \mathrm{~min}$ at $94^{\circ} \mathrm{C}$; denaturation for $45 \mathrm{~s}$ at $94^{\circ} \mathrm{C}$; annealing for $40 \mathrm{~s}$ at $55^{\circ} \mathrm{C}$; extension for $70 \mathrm{~s}$ at $72^{\circ} \mathrm{C}, 37 \mathrm{cycles}$; and a final extension for $7 \mathrm{~min}$ at $72^{\circ} \mathrm{C}$.

Genetic Diversity Analysis. According to the bands in the electrophoretogram, the positions with the same migration rate on the gel and with DNA bands were recorded as "1", and those without DNA bands were recorded as "0." POPGEN 1.32 software [32] was used to calculate the genetic parameters: (1) percentage of polymorphic loci $(P P B)$; (2) number of alleles $\left(N_{a}\right)$ and number of effective alleles $\left(N_{e}\right) ;(3)$ expected heterozygosity $(\mathrm{He})$; (4) Nei's genetic diversity index $(H)$ and Shannon's information index (I); (5) total genetic diversity index $\left(H_{t}\right)$ and genetic diversity index in populations $\left(H_{s}\right)$; (6) genetic differentiation coefficient $\left(G_{s t}=1-H_{s} / H_{t}\right)$ and 
TABLE 1: Locations of six natural populations in Opisthopappus Shih.

\begin{tabular}{|c|c|c|c|c|c|}
\hline Populations & Locality & Sample size & Longitude $(E)$ & Latitude $(N)$ & Altitude $(m)$ \\
\hline \multicolumn{6}{|c|}{ O. taihangensis } \\
\hline YTS & Yuntaishan Mountains, Xiuwu, Henan province & 49 & $113.138^{\circ}$ & $35.450^{\circ}$ & 1070 \\
\hline GS & Guanshan Mountains, Huixian, Henan province & 49 & $113.530^{\circ}$ & $35.562^{\circ}$ & 1057 \\
\hline WML & Wangmangling Mountains, Lingchuan, Shanxi province & 8 & $113.594^{\circ}$ & $35.687^{\circ}$ & 1550 \\
\hline \multicolumn{6}{|l|}{ O. longilobus } \\
\hline $\mathrm{LZ}$ & Taihang Grand Canyon, Linzhou, Henan province & 42 & $113.691^{\circ}$ & $36.170^{\circ}$ & 684 \\
\hline LFS & Lufengshan Mountains, Fengfeng, Hebei province & 18 & $113.918^{\circ}$ & $36.404^{\circ}$ & 999 \\
\hline $\mathrm{XT}$ & Xingtai Grand Canyon, Xingtai, Hebei province & 34 & $113.872^{\circ}$ & $37.114^{\circ}$ & 532 \\
\hline
\end{tabular}

TABLE 2: Nei's total genetic diversity index $\left(H_{t}\right)$, genetic diversity index in populations $\left(H_{s}\right)$, genetic differentiation coefficient $\left(G_{s t}\right)$, and gene flow $\left(N_{m}\right)$ in Opisthopappus.

\begin{tabular}{|c|c|c|c|c|}
\hline Taxa & $H_{t}$ & $H_{s}$ & $G_{s t}$ & $N_{m}$ \\
\hline Opisthopappus & $0.2139 \pm 0.0316$ & $0.2042 \pm 0.0286$ & 0.0453 & 10.562 \\
\hline O. taihangensis & $0.1930 \pm 0.0314$ & $0.1401 \pm 0.0149$ & 0.2740 & 1.325 \\
\hline O. longilobus & $0.2173 \pm 0.0301$ & $0.1948 \pm 0.0235$ & 0.1034 & 4.336 \\
\hline
\end{tabular}

gene flow $\left[N_{m}=\left(1-G_{s t}\right) / 2 G_{s t}\right]$; and (7) Nei's genetic distance (D) and genetic identity $\left(I_{N}\right)$. Analysis of molecular variance (AMOVA) in GENALEX 6.4 software package [33] was used to calculate the genetic variation and genetic distance $\left(\Phi_{s t}\right)$. Based on Nei's genetic distance, NTSYS-pc 2.10e software [34] was used to conduct the unweighted pair-group method with arithmetic mean (UPGMA) cluster analysis. In addition, TFPGA software [35] was adopted to perform the Mantel test of correlation between the genetic and geographical distance between species groups.

\section{Results}

Genetic Diversity. A total of 253 ISSR bands were amplified, 230 of which were polymorphism bands. The $P P B$ at genus level was $90.91 \%, 90.12 \%$ for O. taihangensis, and $95.21 \%$ for $O$. longilobus. Generally, at genus level, Opisthopappus showed higher genetic diversity. Nei's total genetic diversity index of Opisthopappus $\left(H_{t}\right)$ was 0.2139 (Table 2). Meanwhile, at species level, the total genetic diversity index $\left(H_{t}=0.2173\right)$ and genetic diversity index in populations $\left(H_{s}=0.1948\right)$ of O. longilobus Shih were slightly higher than those of Opisthopappus Shih $\left(H_{t}=0.1930, H_{s}=0.1401\right)$.

The percentage of polymorphic loci $(P P B)$, number of alleles $\left(N_{a}\right)$, number of effective alleles $\left(N_{e}\right)$, expected heterozygosity $(\mathrm{He})$, Nei's genetic diversity index $(H)$, and Shannon's information index $(I)$ at genus level were $90.91 \%, 1.9467$, $1.3452,0.1675,0.2121$, and 0.3372 , respectively (Table 3 ). At species level, all genetic parameters of $O$. longilobus were higher than those of $O$. taihangensis. Moreover, among the three populations of $O$. taihangensis, all genetic parameters of the GS population were the highest, whereas those of WML were the lowest. Meanwhile, among three populations of $O$. longilobus, all genetic parameters of the LZ population were the highest, whereas those of LFS were the lowest.
At population level, all the genetic parameters of LZ were the highest, whereas those of WML were the lowest (Table 3).

Genetic Differentiation and Gene Flow. Genetic differentiation coefficient $\left(G_{s t}\right)$ between two species of Opisthopappus was 0.0453, which was lower than that among populations at species level (Table 2). Furthermore, genetic differentiation among populations in $O$. taihangensis was slightly higher than O. longilobus (Table 2).

At population level, genetic differentiation coefficient $\left(\Phi_{s t}\right)$ arranged from 0.122 to 0.427 (i.e., an average of 0.240 ) (Table 4). The coefficient between LFS and WML was the highest (0.427), whereas that between XT and LFS was the lowest (0.122). For $O$. taihangensis, genetic differentiation between GS and YTS, GS and WML, and YTS and WML increased gradually; similarly, for O. longilobus, genetic differentiation between XT and LFS, LZ and XT, and LZ and LFS also increased gradually (Table 4).

Genetic Variation and Structure. The AMOVA results showed that most of genetic variation in Opisthopappus existed within population (77.87\%), following among populations (16.15\%), and between species (5.98\%) (Table 5). Most of the genetic variation of the two species, respectively, also existed within populations. Moreover, genetic variation of $O$. longilobus within populations $(84.95 \%)$ was slightly higher than that of O. taihangensis $(80.45 \%)$.

Cluster Analysis and Correlation between Geographical Distance and Genetic Distance. At population level, genetic distance between XT and GS population was lowest (0.0277) and that between LZ and WML was highest (0.1552) (Table 6). According to UPGMA cluster analysis based on Nei's genetic distance (Figure 2), the respective populations of two species were not clustered into one clade at first, while XT and GS populations were clustered firstly and were then composed 
TABLE 3: Percentage of polymorphic loci $(P P B)$, number of alleles $\left(N_{a}\right)$, number of effective alleles $\left(N_{e}\right)$, expected heterozygosity $(H e)$, Nei's genetic diversity $(H)$, and Shannon's information index $(I)$ in Opisthopappus.

\begin{tabular}{|c|c|c|c|c|c|c|}
\hline Populations & $P P B$ & $N_{a}$ & $N_{e}$ & $\mathrm{He}$ & $H$ & $I$ \\
\hline \multicolumn{7}{|l|}{ O. taihangensis } \\
\hline YTS & $62.45 \%$ & $1.6245 \pm 0.4852$ & $1.2748 \pm 0.3729$ & $0.1588 \pm 0.0124$ & $0.1588 \pm 0.1966$ & $0.2423 \pm 0.2755$ \\
\hline GS & $71.54 \%$ & $1.7154 \pm 0.4521$ & $1.2713 \pm 0.3375$ & $0.1663 \pm 0.0114$ & $0.1663 \pm 0.1806$ & $0.2618 \pm 0.2547$ \\
\hline WML & $38.74 \%$ & $1.3874 \pm 0.4881$ & $1.1482 \pm 0.2637$ & $0.0954 \pm 0.0094$ & $0.0954 \pm 0.1493$ & $0.1538 \pm 0.2220$ \\
\hline Mean & $57.58 \%$ & $1.5758 \pm 0.4751$ & $1.2314 \pm 0.3247$ & $0.1402 \pm 0.0111$ & $0.1402 \pm 0.1755$ & $0.2193 \pm 0.2507$ \\
\hline Species level & $90.12 \%$ & $1.9012 \pm 0.2990$ & $1.3062 \pm 0.3569$ & $0.1401 \pm 0.0065$ & $0.1842 \pm 0.1867$ & $0.2895 \pm 0.2562$ \\
\hline \multicolumn{7}{|l|}{ O. longilobus } \\
\hline LZ & $93.28 \%$ & $1.9328 \pm 0.2509$ & $1.3439 \pm 0.3286$ & $0.2157 \pm 0.0105$ & $0.2157 \pm 0.1675$ & $0.3443 \pm 0.2242$ \\
\hline LFS & $54.15 \%$ & $1.5415 \pm 0.4993$ & $1.2796 \pm 0.3532$ & $0.1665 \pm 0.0120$ & $0.1665 \pm 0.1913$ & $0.2538 \pm 0.2741$ \\
\hline XT & $81.42 \%$ & $1.8142 \pm 0.3897$ & $1.3345 \pm 0.3561$ & $0.2021 \pm 0.0116$ & $0.2021 \pm 0.1851$ & $0.3155 \pm 0.2547$ \\
\hline Mean & $76.28 \%$ & $1.7628 \pm 0.3800$ & $1.3193 \pm 0.3460$ & $0.1948 \pm 0.0114$ & $0.1948 \pm 0.1813$ & $0.3045 \pm 0.2510$ \\
\hline Species level & $95.21 \%$ & $1.9921 \pm 0.0887$ & $1.3599 \pm 0.3403$ & $0.1948 \pm 0.0066$ & $0.2226 \pm 0.1710$ & $0.3542 \pm 0.2245$ \\
\hline \multicolumn{7}{|l|}{ Opisthopappus } \\
\hline Mean & $66.93 \%$ & $1.6693 \pm 0.4276$ & $1.2754 \pm 0.3353$ & $0.1675 \pm 0.0113$ & $0.1675 \pm 0.1784$ & $0.2619 \pm 0.2509$ \\
\hline Genus level & $90.91 \%$ & $1.9467 \pm 0.1939$ & $1.3452 \pm 0.3450$ & $0.1675 \pm 0.0047$ & $0.2121 \pm 0.1764$ & $0.3372 \pm 0.2340$ \\
\hline
\end{tabular}

TABLE 4: Genetic differentiation of PhiPT analysis between populations.

\begin{tabular}{lcccccc}
\hline Populations & YTS & GS & WML & LZ & LFS & XT \\
\hline YTS & $* * * *$ & & & & & \\
GS & 0.131 & $* * * *$ & & & & \\
WML & 0.361 & 0.328 & $* * * *$ & & & \\
LZ & 0.239 & 0.219 & 0.309 & $* * * *$ & & \\
LFS & 0.274 & 0.251 & 0.427 & 0.180 & $* * * *$ & \\
XT & 0.156 & 0.144 & 0.311 & 0.142 & 0.122 & $* * * *$ \\
\hline
\end{tabular}

of YTS and LZ to a clade. WML population had the largest distance to all other populations; thus, it located in the basal of the clustering tree.

The results of Mantel tests showed that geographical distance among populations had no significant correlation with genetic distance $(r=-0.2419, P=0.1845)$. Furthermore, at species level, there was no significant correlation between geographical distance and genetic distance in O. taihangensis $(r=0.7154, P=0.3380)$ and $O$. longilobus $(r=0.6011$, $P=0.3510)$, respectively.

\section{Discussion}

Genetic Diversity. In Opisthopappus, not only at genus level but also at species level, there was high genetic diversity. Nei's genetic diversity and Shannon's information index of $O$. taihangensis (Ling) Shih and O. longilobus Shih were higher than those of herbaceous plants $(H=0.162, I=0.238)$ and plants in narrow fields or endangered plants $(H=$ $0.157, I=0.249)[36,37]$ but were slightly lower than those of Taihangia rupestris, another cliff species endemic to the same area $[22,23]$. These indicated that two species of Opisthopappus both had higher genetic diversity. The degree of genetic diversity in O. longilobus was slightly higher than

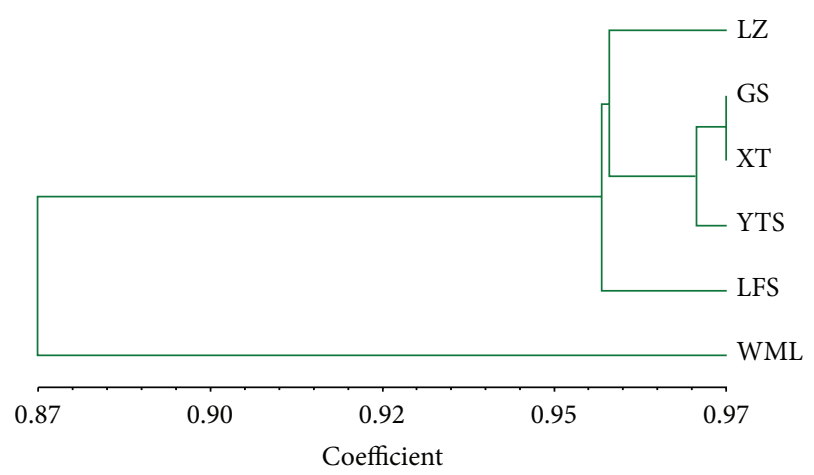

FIGURE 2: UPGMA cluster analysis of the six populations (two species) based on ISSR analysis.

that of $O$. taihangensis. The AMOVA analysis showed that most of the genetic variation existed within populations and LZ had the highest genetic diversity among six populations. T. rupestris also had similar genetic diversity and genetic structure $[22,23]$.

These two taxa (i.e., Opisthopappus and Taihangia) endemic to the Taihang Mountains showed similar genetic structures. For T. rupestris, ancient origin and comprehensive reproductive mechanisms might be the key contributing factors for its higher genetic diversity [23]. T. rupestris produced rich genetic variation through sexual reproduction during the long-term evolutionary process. The coexistence of asexual and sexual reproduction caused these variations to accumulate and spread [23]. Meanwhile, higher genetic diversity in Opisthopappus was closely related to its special habitats, population regeneration, and dispersal. Individuals of Opisthopappus all grow in cliff cracks with a slope of nearly $90^{\circ}$ (Figures 3(a)-3(d)). No conditions for vegetative propagation are present, given that its seeds are small and light and easily spread by gravity and wind (Figure 3(e)). It can be 
TABLE 5: The analysis of molecular variance (AMOVA) in Opisthopappus.

\begin{tabular}{|c|c|c|c|c|c|}
\hline Source of variation & Degrees of freedom & Sums of squares & Variance component & Variation (\%) & $P^{*}$ \\
\hline \multicolumn{6}{|l|}{ Opisthopappus } \\
\hline Between species & 1 & 423.0082 & 1.921 & 5.98 & $<0.001$ \\
\hline Among populations & 4 & 719.6363 & 5.182 & 16.15 & $<0.001$ \\
\hline Within population & 194 & 4847.7555 & 24.988 & 77.87 & $<0.001$ \\
\hline Total & 199 & 5990.4000 & 32.091 & & \\
\hline \multicolumn{6}{|l|}{ O. taihangensis } \\
\hline Among populations & 2 & 354.9223 & 5.195 & 19.55 & $<0.001$ \\
\hline Within population & 103 & 2201.3418 & 21.372 & 80.45 & $<0.001$ \\
\hline Total & 105 & 2556.2641 & 26.567 & & \\
\hline \multicolumn{6}{|l|}{ O. longilobus } \\
\hline Among populations & 2 & 364.7140 & 5.153 & 15.05 & $<0.001$ \\
\hline Within population & 91 & 2646.4136 & 29.081 & 84.95 & $<0.001$ \\
\hline Total & 93 & 3011.1276 & 34.234 & & \\
\hline
\end{tabular}

${ }^{*} P$ values are the probabilities of having a more extreme variance component than the observed values by chance alone. Probabilities calculated by 1000 random permutations of individuals across populations.

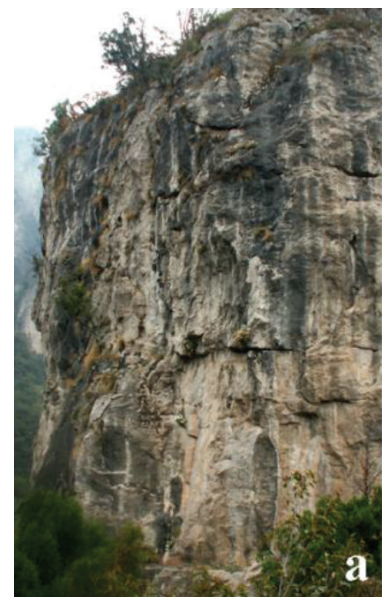

(a)

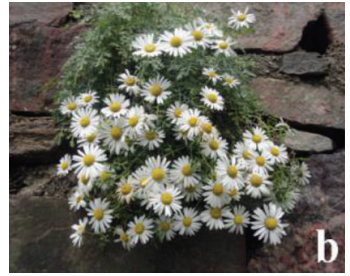

(b)

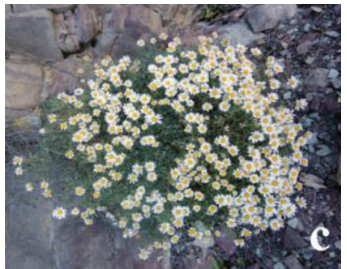

(c)

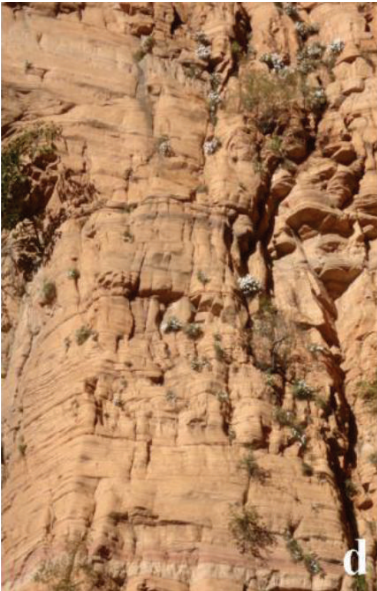

(d)

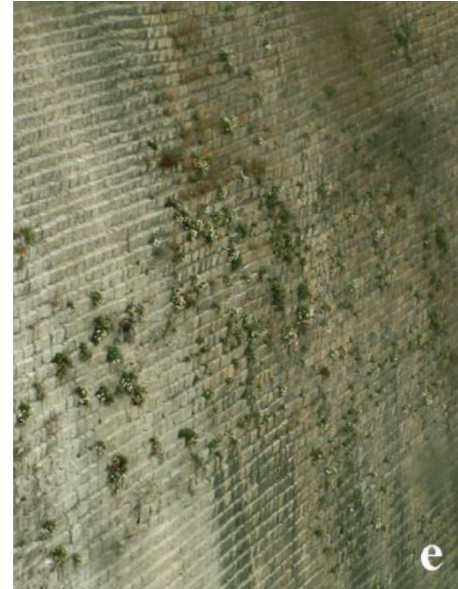

(e)

Figure 3: Cliff habitats and flowering plants in Opisthopappus. (a and b) O. taihangensis; (c and d) O. longilobus; (e) distributing condition of $O$. taihangensis in a manmade reservoir dam (more and more plants from the upper to the lower of dam and distribution scope showing triangle) and that reflecting the seed dispersal by wind and gravity.

TABLE 6: Nei's genetic identity (above diagonal) and genetic distance (below diagonal) in populations.

\begin{tabular}{lcccccc}
\hline Populations & YTS & GS & WML & LZ & LFS & XT \\
\hline YTS & $* * * *$ & 0.9681 & 0.8642 & 0.9484 & 0.9410 & 0.9684 \\
GS & 0.0324 & $* * * *$ & 0.9044 & 0.9549 & 0.9531 & 0.9727 \\
WML & 0.1460 & 0.1004 & $* * * *$ & 0.8562 & 0.8648 & 0.8688 \\
LZ & 0.0529 & 0.0462 & 0.1552 & $* * * *$ & 0.9518 & 0.9634 \\
LFS & 0.0609 & 0.0480 & 0.1453 & 0.0494 & $* * * *$ & 0.9722 \\
XT & 0.0321 & 0.0277 & 0.1407 & 0.0372 & 0.0282 & $* * * *$ \\
\hline
\end{tabular}

inferred that sexual reproduction is the main reproductive mode under natural conditions. This reproductive mode is beneficial to gene flow among individuals and among populations, resulting in an increase and maintenance of the degree of genetic diversity. Moreover, O. longilobus is distributed in the north of the Taihang Mountains. The environmental conditions such as precipitation, humidity, and temperature therein are more wretched than those in the distribution area of $O$. taihangensis. Therefore, natural regeneration can hardly occur, with slower alternation of generations. Hence, its measured genetic diversity is higher than that of $O$. taihangensis. LZ population has the highest genetic diversity, which may be attributable to the fact that it is in the intermediate zone between $O$. taihangensis and O. longilobus with special habitats, resulting in rich variation within population and an increased degree of genetic diversity.

Genetic Differentiation and Interspecific Differentiation. Genetic differentiation coefficient of $O$. taihangensis $\left(G_{s t}\right)$ is higher than that of endemic and perennial plants $\left(G_{s t}=0.18\right.$ and 0.19 , resp.) $[37,38]$. Furthermore, genetic differentiation 
coefficient of O. longilobus Shih is lower than that of endemic and perennial plants. These indicate the presence of a certain genetic differentiation among populations in O. taihangensis; however genetic differentiation of $O$. longilobus is relatively small. Gene flow at different degrees (1.325 in O. taihangensis and 4.336 in $O$. longilobus) and mating system (sexual reproduction) can be the contributing factors to the current genetic structures in this genus. Low gene flow may cause population to adapt to the local ecological environment, thus accelerating genetic differentiation [39]. Wright [40] asserted that when gene flow $N_{m}>1$, genetic differentiation among populations due to genetic drift can be prevented. For O. taihangensis or O. longilobus, AMOVA showed that genetic variation mostly existed within population $(80.45 \%$ and $84.95 \%$, resp.). A similar phenomenon was found in T. rupestris $[22,23]$, implying that habitat fragmentation and particularity do not cause significant genetic differentiation among populations in these endangered cliff plants endemic to the Taihang Mountains, and instead, promote them to adapt to the special habitats to sustain higher genetic diversity.

A significantly positive correlation exists between genetic and geographical distance for T. rupestris [22, 23] and Centaurea corymbosa Pourret [41], another rare, cliff-dwelling species. By contrast, in the studies on Opisthopappus, the Mantel test revealed that no significant correlation exists between genetic and geographical distance $(r=-0.2419$, $P=0.1845)$. Geographical isolation cannot explain the population differentiation that occurred in Antirrhinum charidemi and A. valentinum (endemic species distributed narrowly) [42] and Arctomecon humilis (an endangered plant) [43]. The absence of correlation between geographical and genetic distance in these species may be related to the rude interference of human beings at the least [43]. Human activity may break the balance between population migration and adaption, deepen habitat fragmentation [42], reduce the size of proper migration sites, and increase the isolated distance among populations $[22,44,45]$. O. taihangensis and O. longilobus both have a certain medical value, which led to serious human picking and mining. These activities cause great impact on the effective size of populations and their dispersal, affecting the natural gene flow among populations. They can explain the absence of correlation between geographical and genetic distance.

In T. rupestris, the clustering of the different populations into the two major clades agreed with the geographical distribution and its classification into the two varieties [22, 23]. The moderate degree of gene flow shaped the genetic profiles of $T$. rupestris, homogenizing the genetic diversity of the two varieties, namely, T. rupestris var. rupestris and T. rupestris var. ciliate [23]. The two varieties were classified based on the difference in their leaf morphology [7]. They are distributed in the south and north of the Taihang Mountains, respectively. O. taihangensis and O. longilobus are similar to T. rupestris in terms of morphological difference and geographic distribution; however, the clustering result of this study shows that the respective populations of these two species do not gather but cross-cluster. Hence, interspecific genetic differentiation between two species is not significant.
Their interspecific differentiation is significantly later than the two varieties of $T$. rupestris [1]. O. taihangensis and O. longilobus are classified according to the split series of the upper leaves and the presence or absence of bracts below involucres. In $O$. taihangensis, the leaves are bipinnatifid and have pubescences attached to both sides; it does not have bracts below involucres. By contrast, most of the leaves of $O$. longilobus are pinnatifid except for basal leaves (bipinnatifid or near the bipinnatifid) and all leaves are smooth without pubescences; in addition, it has a pair of bracts below involucres [1]. Almost no genetic differentiation was found between the two subspecies of Dryas octopetala L. (Rosaceae) despite their significant morphological differences [46]. For Opisthopappus, the speed of interspecific genetic differentiation can be less than the speed of morphological differentiation, which may be closely related to mating system. Sexual reproduction will promote gene flow among populations, even between species, reducing the interspecific genetic differentiation. Meanwhile, in T. rupestris, the main mode of population regeneration is vegetative propagation [22], which is favorable to fix genetic characteristics in the level of population, subspecies, or species and thus enhance genetic differentiation.

Genetic Diversity and Resource Protection. The degree of genetic diversity to a certain extent reflects the capacity of species to adapt to the external environment. It not only restricts the capacity of individual and species to adapt to the environmental changes but also provides very important information for the realization and protection of species [14, 47]. The results in this study have shown that the endangered status in Opisthopappus is not caused by the degree of genetic diversity but by population regeneration block and the difficulty to recovery due to habitat destruction and fragmentation. Therefore, an effective protection procedure should be developed to avoid a serious endangered situation; for example, in situ conservation through establishing a nature reserve, ex situ conservation in areas with serious habitat destruction, and manual promotion to natural regeneration can be carried out.

\section{Authors' Contribution}

Rongmin Guo and Lihua Zhou contributed equally to this work.

\section{Acknowledgments}

This work was supported by the National Natural Science Foundation of China (Grant nos. 31101571 and 31170656), Zhejiang Provincial Natural Science Foundation of China (Grant no. Y3110357), and Young Teacher Innovation Team Item of Zhejiang Agriculture and Forestry University (Grant no. 2010RC01).

\section{References}

[1] C. Shih, "Opisthopappus Shih-a new genus of compositae from China," Acta Phytotaxonomica Sinica, vol. 32, pp. 110-112, 1979. 
[2] C. Shih and G. X. Fu, Angiospermae, Dicotyledoneae, Compositae (3) Anthemideae, Angiospermae. Flora Republicae Popularis Sinicae 76(1), Science Press, Beijing, China, 1983.

[3] D. Y. Yang, X. Hu, Z. H. Liu, and H. Zhao Huien, "Intergeneric hybridizations between Opisthopappus taihangensis and Chrysanthemum lavandulifolium," Scientia Horticulturae, vol. 125, no. 4, pp. 718-723, 2010.

[4] H. B. Zhao, F. D. Chen, S. M. Chen, G. Wu, and W. Guo, "Molecular phylogeny of Chrysanthemum, Ajania and its allies (Anthemideae, Asteraceae) as inferred from nuclear ribosomal ITS and chloroplast trnL-F IGS sequences," Plant Systematics and Evolution, vol. 284, no. 3, pp. 153-169, 2010.

[5] F. P. Tang, H. B. Wang, S. M. Chen, F. Chen, N. Teng, and Z. Liu, "First intergeneric hybrids within the tribe Anthemideae Cass. III. Chrysanthemum indicum L. Des Moul. $\times$ Opisthopappus taihangensis (Ling) Shih," Biochemical Systematics and Ecology, vol. 43, pp. 87-92, 2012.

[6] L. G. Fu and J. M. Jin, The Red Rata Book of China's plants: Rare and endangered Species Volume 1, Science Press, Beijing, China, 1992.

[7] D. J. Yu and C. L. Li, "Taihangia Yu et Li-a new genus of Rosaceae from China," Acta Phytotaxonomy Sinica, vol. 18, pp. 469-472, 1980.

[8] W. B. Tang, "A floristic analysis of the seed plants in the middlesouth area of east slope of Taihang Mountains," Bulletin of Botanical Research, vol. 25, no. 3, pp. 366-372, 2005.

[9] W. M. Ru, G. P. Zhang, and J. T. Zhang, "Study on wild plant resources in the Southern segment of Taihang Mountains, Shanxi," Journal of Shanxi University, vol. 30, pp. 411-414, 2007.

[10] J. L. Hamrick and M. J. W. Godt, "Allozyme diversity in plant species," in Plant Population Genetics, Breeding and Genetic Resourses, A. H. D. Brown, M. T. Clegg, A. L. Kahler, and B. S. Weir, Eds., pp. 43-63, Sinauer Associates, Sunderland, Mass, USA, 1989.

[11] B. Colas, I. Olivieri, and M. Riba, "Centaurea corymbosa, a cliff-dwelling species tottering on the brink of extinction: a demographic and genetic study," Proceedings of the National Academy of Sciences of the United States of America, vol. 94, no. 7, pp. 3471-3476, 1997.

[12] B. Jones, C. Gliddon, and J. E. G. Good, "The conservation of variation in geographically peripheral populations: Lloydia serotina (Liliaceae) in Britain," Biological Conservation, vol. 101, no. 2, pp. 147-156, 2001.

[13] J. Segarra-Moragues and P. Catalán, "Low allozyme variability in the critically endangered Borderea chouardii and in its congener Borderea pyrenaica (Dioscoreaceae), two paleoendemic relicts from the central pyrenees," International Journal of Plant Sciences, vol. 163, no. 1, pp. 159-166, 2002.

[14] M. Hughes, P. M. Hollingsworth, and A. G. Miller, "Population genetic structure in the endemic begonia of the Socotra archipelago," Biological Conservation, vol. 113, no. 2, pp. 277-284, 2003.

[15] U. Matthes-Sears, C. H. Nash, and D. W. Larson, "Constrained growth of trees in a hostile environment: the role of water and nutrient availability for Thuja occidentalis on cliff faces," International Journal of Plant Sciences, vol. 156, no. 3, pp. 311319, 1995.

[16] J. Mattner, G. Zawko, M. Rossetto, S. L. Krauss, K. W. Dixon, and K. Sivasithamparam, "Conservation genetics and implications for restoration of Hemigenia exilis (Lamiaceae), a serpentine endemic from Western Australia," Biological Conservation, vol. 107, no. 1, pp. 37-45, 2002.
[17] G. Zawko, S. L. Krauss, K. W. Dixon, and K. Sivasithamparam, "Conservation genetics of the rare and endangered Leucopogon obtectus (Ericaceae)," Molecular Ecology, vol. 10, no. 10, pp. 2389-2396, 2001.

[18] T. L. Maguire and M. Sedgley, "Genetic diversity in Banksia and Dryandra (Proteaceae) with emphasis on Banksia cuneata, a rare and endangered species," Heredity, vol. 79, no. 4, pp. 394401, 1997.

[19] Y. C. Chiang, K. H. Hung, B. A. Schaal, X.-J. Ge, T.-W. Hsu, and T.-Y. Chiang, "Contrasting phylogeographical patterns between mainland and island taxa of the Pinus luchuensis complex," Molecular Ecology, vol. 15, no. 3, pp. 765-779, 2006.

[20] S. S. Luan, T. Y. Chiang, and X. Gong, "High genetic diversity vs. low genetic differentiation in Nouelia insignis (Asteraceae), a narrowly distributed and endemic species in China, revealed by ISSR fingerprinting," Annals of Botany, vol. 98, no. 3, pp. 583589, 2006.

[21] R. J. Abbott, "Variation within common groundsel, Senecio vulgaris L.I. genetic response to spatial variations of the environment," New Phytologist, vol. 76, no. 1, pp. 153-164, 1976.

[22] M. Tang, F. H. Yu, X. B. Jin, and S. Ge, "High genetic diversity in the naturally rare plant Taihangia rupestris Yu et Li (Rosaceae) dwelling only cliff faces," Polish Journal of Ecology, vol. 58, no. 2, pp. 241-248, 2010.

[23] H. W. Wang, X. M. Fang, Y. Z. Ye, Y. Cheng, and Z. Wang, "High genetic diversity in Taihangia rupestris Yu et Li, a rare cliff herb endemic to China, based on inter-simple sequence repeat markers," Biochemical Systematics and Ecology, vol. 39, no. 4-6, pp. 553-561, 2011.

[24] L. F. Yao, M. H. Dong, and Y. S. Mao, "Study on tissue culture of Opisthopappus taihangensis," Chinese Agricultural Science Bulletin, vol. 20, no. 6, pp. 29-31, 2004.

[25] Y. Z. Sang, M. Sun, and Q. X. Zhang, "Study on cell suspension culture of Opisthopappus taihangensis," Journal of Henan Agricultural University, vol. 45, pp. 177-182, 2011.

[26] H. B. Zhao, C. Li, F. P. Tang, F. D. Chen, and S. M. Chen, "Chromosome numbers and morphology of eighteen Anthemideae (Asteraceae) taxa from China and their systematic implications," Caryologia, vol. 62, no. 4, pp. 288-302, 2009.

[27] J. Li, S. M. Chen, F. D. Chen, and W. M. Fang, "Karyotype and meiotic analyses of six species in the subtribe Chrysantheminae," Euphytica, vol. 164, no. 1, pp. 293-301, 2008.

[28] J. Li, N. J. Teng, F. D. Chen, S. M. Chen, C. Q. Sun, and W. M. Fang, "Reproductive characteristics of Opisthopappus taihangensis (Ling) Shih, an endangered Asteraceae species endemic to China," Scientia Horticulturae, vol. 121, no. 4, pp. 474-479, 2009.

[29] Y. H. Gao, P. F. Dai, Z. F. Ji, X. Han, and Y. L. Wang, "Studies on pollen morphology of Opisthopappus Shih," Acta Botanica Boreali-Occidentalia Sinica, vol. 31, pp. 2464-2472, 2011.

[30] Y. L. Wang and G. Q. Yan, "Genetic diversity and population structure of Opisthopappus longilobus and Opisthopappus taihangensis (Asteraceae) in China determined using sequence related amplified polymorphism markers," Biochemical Systematics and Ecology, vol. 49, pp. 115-124, 2013.

[31] M. W. Lassner, P. Peterson, and J. I. Yoder, "Simultaneous amplification of multiple DNA fragments by polymerase chain reaction in the analysis of transgenic plants and their progeny," Plant Molecular Biology Reporter, vol. 7, no. 2, pp. 116-128, 1989.

[32] F. C. Yeh, R. C. Yand, T. J. B. Boyle, Z. H. Ye, and J. X. Mao, POPGENE, The User-Friendly Sharew Are for Population Genetic 
Analysis.Ver. 1.32, Molecular Biology and Biochemistry Center, University of Alberta, Alberta, Canada, 1997.

[33] R. Peakall and P. E. Smouse, "GENALEX 6: genetic analysis in Excel. Population genetic software for teaching and research," Molecular Ecology Notes, vol. 6, no. 1, pp. 288-295, 2006.

[34] F. J. Rohlf, NTSYS-Pc. Numerical Taxonomy and Multi-Variate Analysis System, Version 2.1, Exeter Software, Setauket, NY, USA, 2000.

[35] M. P. Miller, Tools For Population Genetic Analysis (TFPGA), Version 1.3, Department of Biological Sciences, Northern Arizona University, Flagstaff, Ariz, USA, 1997.

[36] D. Q. Zhang and Y. P. Yang, "A statistical and comparative analysis of genetic diversity detected by different molecular markers," Acta Botanica Yunnanica, vol. 30, pp. 159-167, 2008.

[37] H. Nybom, "Comparison of different nuclear DNA markers for estimating intraspecific genetic diversity in plants," Molecular Ecology, vol. 13, no. 5, pp. 1143-1155, 2004.

[38] H. Nybom and I. V. Bartish, "Effects of life history traits and sampling strategies on genetic diversity estimates obtained with RAPD markers in plants," Perspectives in Plant Ecology, Evolution and Systematics, vol. 3, no. 2, pp. 93-114, 2000.

[39] M. Sun and K. C. Wong, "Genetic structure of three orchid species with contrasting breeding systems using RAPD and allozyme markers," American Journal of Botany, vol. 88, no. 12, pp. 2180-2188, 2001.

[40] S. Wright, "Evolution in Mendelian Populations," Genetics, vol. 16, pp. 97-159, 1931.

[41] H. Freville, F. Justy, and I. Olivieri, "Comparative allozyme and microsatellite population structure in a narrow endemic plant species, Centaurea corymbosa Pourret (Asteraceae)," Molecular Ecology, vol. 10, no. 4, pp. 879-889, 2001.

[42] L. Allphin, M. D. Windham, and K. T. Harper, "Genetic diversity and gene flow in the endangered dwarf bear poppy, Arctomecon humilis (Papaveraceae)," American Journal of Botany, vol. 85, no. 9, pp. 1251-1261, 1998.

[43] I. Mateu-Andrés and J. G. Segarra-Moragues, "Population subdivision and genetic diversity in two narrow endemics of Antirrhinum L.," Molecular Ecology, vol. 9, no. 12, pp. 2081-2087, 2000.

[44] H. Andren, "Effects of habitat fragmentation on birds and mammals in landscapes with different proportions of suitable habitat: a review," Oikos, vol. 71, no. 3, pp. 355-366, 1994.

[45] S. R. Ballal, S. A. Fore, and S. I. Guttman, "Apparent gene flow and genetic structure of Acer saccharum subpopulations in forest fragments," Canadian Journal of Botany, vol. 72, no. 9, pp. 1311-1315, 1994.

[46] K. N. Max, S. K. Mouchaty, and K. E. Schwaegerle, "Allozyme and morphological variation in two subspecies of Dryas octopetala (Rosaceae) in Alaska," American Journal of Botany, vol. 86, no. 11, pp. 1637-1644, 1999.

[47] P. M. Hogbin and R. Peakall, "Evaluation of the contribution of genetic research to the management of the endangered plant Zieria prostrata," Conservation Biology, vol. 13, no. 3, pp. 514$522,1999$. 

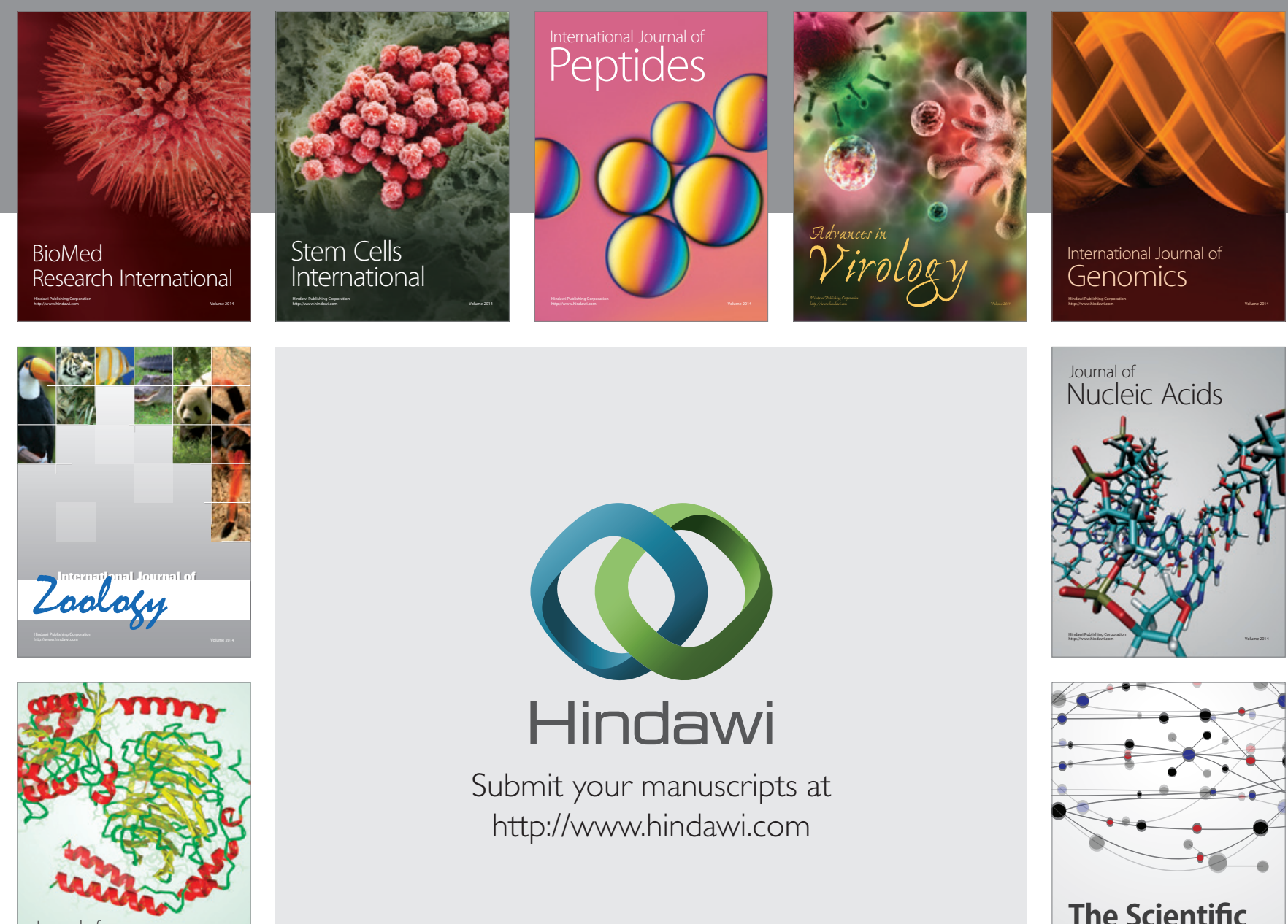

Submit your manuscripts at

http://www.hindawi.com

Journal of
Signal Transduction
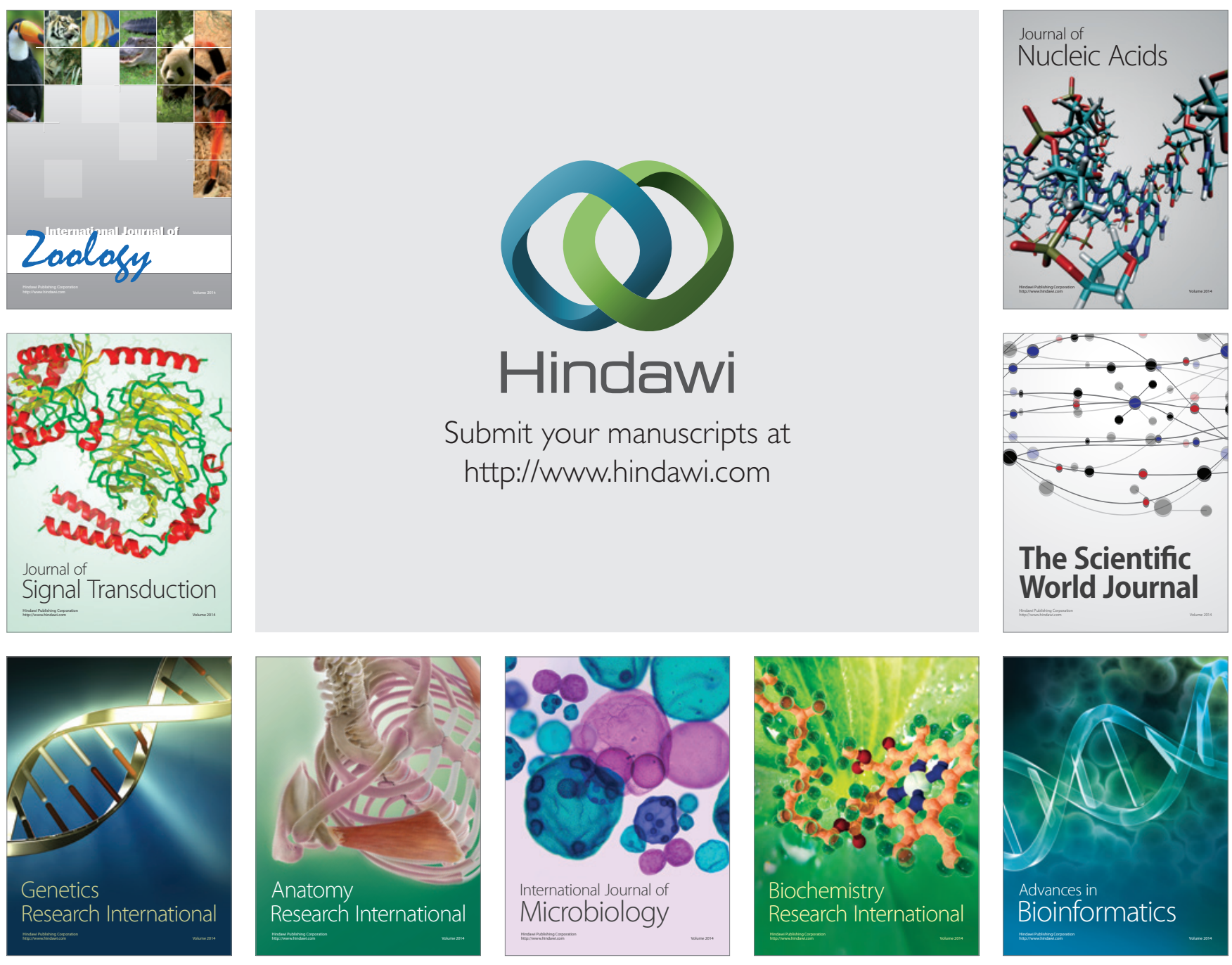

The Scientific World Journal
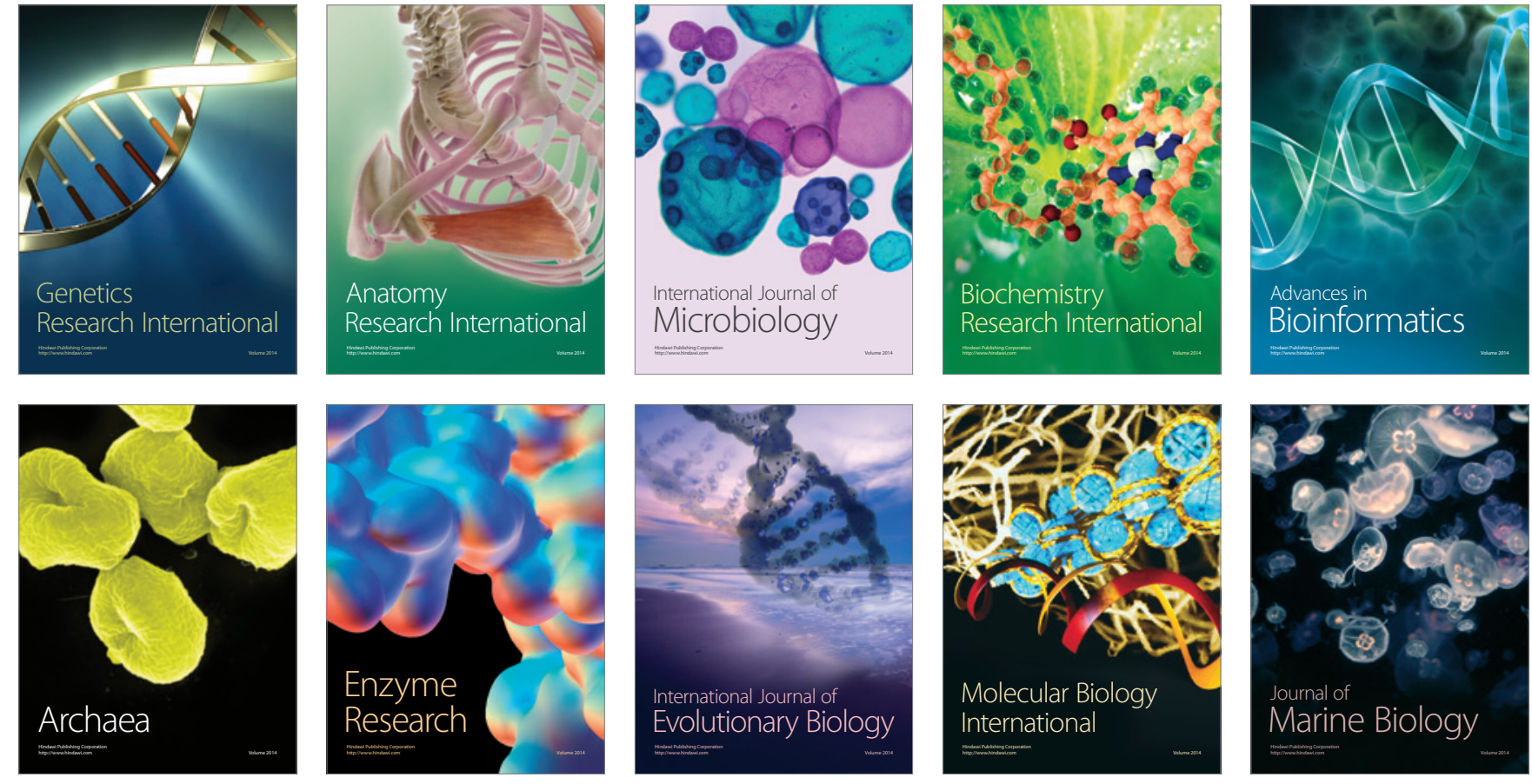